\title{
Agir educativo-comunicativo na relação de assistentes sociais com familiares e usuários: a integralidade no cuidado em saúde mental Educational-communicative action in the relationship of social workers with family and users: integrality in mental health care
}

\author{
Priscila Schacht Cardozo $0^{\mathrm{a}, \mathrm{b}}$ \\ (i) https://orcid.org/0000-0002-4625-2794 \\ E-mail: prish_cardozo®hotmail.com \\ Fabiane Ferraz ${ }^{\mathrm{a}}$ \\ (iD) https://orcid.org/0000-0003-1782-6784 \\ E-mail: olaferrazœgmail.com.br \\ Silvio Yasuic \\ (iD) https://orcid.org/0000-0001-5015-6634 \\ E-mail: silvioyasuiळgmail.com

\section{Diego Floriano de Souzad} \\ (iD) https://orcid.org/0000-0002-2597-7104 \\ E-mail: diegoflorianodesouzaळhotmail.com

\section{Jacks Soratto ${ }^{\mathrm{a}}$} \\ (iD) https://orcid.org/0000-0002-1339-7268 \\ E-mail: jacksळunesc.net \\ aUniversidade do Extremo Sul Catarinense. Programa de \\ Pós-Graduação em Saúde Coletiva. Criciúma, SC, Brasil. \\ bUniversidade Federal de Santa Catarina. Programa de \\ Pós-Graduação em Saúde Coletiva. Florianópolis, SC, Brasil. \\ 'Universidade Estadual Paulista. Departamento de Psicologia \\ Social e Educacional. Assis, SP, Brasil. \\ dUniversidade do Extremo Sul Catarinense. Programa de \\ Residência Multiprofissional em Atenção Básica/Saúde da \\ Família. Criciúma, SC, Brasil.
}

\section{Correspondência}

Priscila Schacht Cardozo

Av. Universitária, I.105. Criciúma, SC, Brasil. CEP 88806-000.

\section{Resumo}

Este trabalho tem por objetivo provocar reflexões sobre o potencial das relações humanas para o cuidado em saúde mental a partir da articulação entre o agir educativo de Paulo Freire e o agir comunicativo de Jürgen Habermas, propondo um construto teórico denominado "agir educativocomunicativo" na relação das/dos assistentes sociais com familiares e usuárias/os no processo de trabalho desenvolvido em Centros de Atenção Psicossocial. O construto teórico do agir educativocomunicativo emergiu de categorias fundamentais, tais como: a escuta, o diálogo, a linguagem, a cultura, a horizontalidade e a educação. Além das categorias que emergem da relação entre Habermas e Freire, é possível acrescentar ainda o cuidado, enquanto categoria também fundamental para o agir educativo-comunicativo. A partir dos preceitos antimanicomiais, o agir educativo-comunicativo tem potencial para fortalecer os vínculos familiares e comunitários enquanto intervenção técnicooperativa do serviço social. Para tanto, faz-se necessária uma intervenção potente de educação permanente em saúde com as/os assistentes sociais, no sentido de fortalecer os princípios antimanicomiais na prática profissional, de ampliar a perspectiva histórica sobre a Reforma Psiquiátrica e de fomentar um conceito de educação que seja emancipadora e, por consequência, antimanicomial, baseada no projeto ético-político da profissão.

Palavras-chave: Saúde Mental; Serviço Social; Integralidade em Saúde; Educação em Saúde; Cuidados Integrais de Saúde. 
This work aims to provoke reflections on the potential of human relations in mental health care by articulating Paulo Freire's educational action and Jürgen Habermas's communicative action, proposing a theoretical construct called "educativecommunicative action" for the relationship of social workers with family members and users of Psychosocial Care Centers. The theoretical construct of educational-communicative action emerged from fundamental categories, such as: listening, dialogue, language, culture, horizontality and education. In addition to the categories that emerge from the relation between Habermas and Freire, care can also be added as a fundamental category for the educational-communicative action. From the anti-asylum precepts, the educational-communicative action has the potential to strengthen family and community bonds, as an operative technical intervention of social work. To do this, a potent permanent health education intervention is needed among the social workers in order to strengthen the anti-asylum principles in professional practice, to broaden the historical perspective on the Psychiatric Reform and to encourage a concept of education that is emancipatory and, consequently, antiasylum, based on the ethical-political project of the profession.

Keywords: Mental Health; Social Work; Integrality in Health; Health Education; Integral Health Care.
Desde a década de 1980, o modelo de cuidado em saúde mental está em processo de transformação no Brasil, por meio dos ideais do Movimento da Luta Antimanicomial e da Reforma Psiquiátrica, que mobilizaram importantes propostas para um novo conceito de atenção e cuidado à "doença mental" (Vasconcelos, 2016). Nesse processo de mudança, duas transformações foram fundamentais para a proposta reflexiva que ora apresentaremos: a inclusão da família no processo de cuidado da usuária e do usuário, e o cuidado em saúde mental promovido por equipes multidisciplinares, não mais se limitando à psiquiatria, pois o rompimento com o modelo que centraliza as ações na figura de único profissional oportuniza que, entre outras áreas, o serviço social se faça presente nesse contexto.

Anterior ao Movimento de Luta Antimanicomial e às ideias da Reforma Psiquiátrica, o isolamento era o método primordial no tratamento de pessoas com “doenças” mentais. 0 manicômio exclui a/o usuária/o do mundo e, por consequência, de sua família, para "cuidar" de sua "doença mental". Sob esse prisma, as ideias da Reforma Psiquiátrica influenciaram diretamente o projeto ético-político do serviço social e, na saúde mental, a família assume um papel de destaque no cuidado à usuária e ao usuário que precisa ser problematizado criticamente (Santos et al., 2016; Tuon, 2011). Logo, a família passa a ser um espaço com potencial positivo para a promoção de cuidado, mas como tal, também precisa ser cuidada, além de requisitar a articulação de uma rede que acolha suas demandas nos territórios onde vivem, a qual deveria ter como protagonistas os serviços desenvolvidos pelos Centros de Atenção Psicossocial (Caps) e as equipes de Estratégia de Saúde da Família (Lima, 2015; Pimenta; Romagnoli, 2008; Santos et al., 2016).

Nesse contexto, este trabalho tem por objetivo provocar reflexões sobre o potencial das relações humanas para o cuidado em saúde mental a partir da articulação entre o agir educativo de Paulo Freire e o agir comunicativo de Jürgen Habermas, propondo um construto teórico denominado "agir educativo-comunicativo" na relação das/os assistentes sociais com familiares no processo de trabalho desenvolvido em Caps. 
Agir comunicativo: diálogos teóricos para mobilizar mudanças nos
contextos da saúde mental

O teórico do agir comunicativo (ou ação comunicativa) é o filósofo alemão Jürgen Habermas, que assume uma corrente de pensamento embasada na Escola de Frankfurt e teve proximidade importante com outros filósofos como Adorno em Heidelberg. Sua construção teórica está entre a filosofia e a sociologia e tem uma abordagem de caráter transversal para diversas áreas do conhecimento (Cestari, 2002). Neste texto, abordaremos suas ideias em proximidade com as áreas da educação e da saúde, bem como sua compreensão sobre autonomia e emancipação.

$\mathrm{O}$ agir comunicativo proposto por Habermas (2002) manifesta-se na interação de no mínimo duas pessoas - sujeitos da ação comunicativa, que demonstram capacidade de falar e agir por meio de relações interpessoais. Essa comunicação pode acontecer de modo verbal e/ou não verbal, assim, quando se materializa o conceito do agir comunicativo compreende-se a possibilidade de fundamentar com maior propriedade uma ação educativa a partir do contexto das sociedades contemporâneas ocidentais (Rosa, 2015).

Os ditos "sujeitos da ação comunicativa" podem ser compreendidos neste ensaio como uma/um assistente social e uma/um familiar e/ou uma/um usuária/o, os quais, na relação dialógica reflexiva, deveriam construir um espaço de trocas, um espaço acolhedor e, por consequência, uma relação educativa emancipatória, perspectiva educativa fundada na horizontalidade, em que todos ensinam e todos aprendem (Freire, 2011). Logo, por meio dessa lógica de educação, fomenta-se o potencial de promoção do cuidado em saúde mental, sendo que nesses momentos emergem questões objetivas, subjetivas e intersubjetivas carregadas de significados.

O exercício profissional da/o assistente social é composto por diversas dimensões, em especial a dimensão ético-política e a dimensão técnicooperativa, sendo as duas interatuantes no processo de trabalho da profissão. A dimensão técnicooperativa é a forma de aparecer da profissão, aquela que constrói visibilidade e oferece resolubilidade, logo, não é neutra e necessita ser permeada pela dimensão ético-política (Guerra; Backx; Santos, 2017). Na dimensão técnico-operativa no campo da saúde mental, a escuta deveria ser um importante instrumento da/o assistente social, no entanto, é possível observar nas intervenções profissionais uma postura em que a racionalidade está aliada à burocracia, fato que constrói um cenário pouco favorável à escuta no processo de trabalho da/o assistente social.

Saber escutar é a porta de entrada para a construção do diálogo, para o processo de comunicação, sendo que o diálogo não é conversação, pois ele só acontece quando conseguimos escutar (Freire, 2015). Assim, acreditamos que o diálogo, que prevê uma escuta qualificada, para além de um ato político de emancipação de sujeitos, pode ser terapêutico, logo, deve ser incorporado pelos diferentes profissionais da saúde.

O diálogo é caracterizado como uma atividade que está fora e dentro de nós, assim, mobiliza em nós o senso crítico, e sua complexidade permite-nos conseguir perguntar o que acontece conosco quando estamos dialogando, bem como o que acontece quando o diálogo não é oportunizado ou permitido? Nesse sentido, o diálogo é considerado uma prática de não violência, visto que a violência é produzida no momento em que o diálogo sai de cena (Tiburi, 2016).

Para Habermas (2002), o "conhecer" surge de uma relação entre sujeitos que se estabelece pela linguagem, correspondendo ao entendimento de que os sujeitos concebem algo sobre o mundo. Dessa forma, integrar conhecimentos cognitivos-instrumentais com o prático moral e o estético-expressivo torna-se fundamental e, assim sendo, na filosofia da linguagem a racionalidade constitui-se como comunicativa e tem como foco o entendimento (Cestari, 2002).

Essa é a relação entre a linguagem e o mundo que o cuidado em saúde mental requer, em que a necessidade urgente de uma racionalidade comunicativa prática, ética, moral, estética e expressiva, lidando com as vicissitudes da vida cotidiana, faz-se urgente, por meio da horizontalidade das relações, dos diálogos e das construções coletivas, o equilíbrio entre as racionalidades, ora instrumental, ora comunicativa. 
Nesse sentido, a ferramenta do agir comunicativo é a linguagem. Habermas (2002) expressa que essa ferramenta de comunicação tem três funções principais: representativa, interativa e expressiva. A função representativa está materializada no mundo objetivo, no modo como falamos de algo. A função interativa é o nosso mundo social, é o ato de nos comunicarmos com a outra, ou com o outro. E a função expressiva está caracterizada pelo mundo objetivo, na competência que temos de expressar o que temos em mente; nesse sentido, a linguagem assumirá características próprias de cada interlocutor e de cada interlocutora.

Para o pensamento contemporâneo da filosofia habermasiana a sociedade estaria dividida entre dois mundos: o mundo da vida, espaço em que o processo comunicativo acontece, onde estão as relações intersubjetivas, e o mundo do sistema, onde está a organização política e econômica, a macroestrutura. As pessoas estabelecem relações dialéticas com esses dois mundos a todo tempo, ou seja, entre o mundo prático e a ideologia do sistema (Fiedler, 2006).

Nessas tensões dialéticas no campo da saúde mental, tem-se no mundo da vida as dores, as alegrias, o sofrimento, o cuidado, as relações de afeto, os conflitos, as usuárias, os usuários, as/os familiares e a comunidade. No mundo do sistema vive-se uma tensão entre forças: entre as práticas antimanicomiais e as práticas manicomiais, que ora estão distintas e ora estão mescladas. A Figura 1 expressa a intercessão da lógica da filosofia habermasiana com o construto histórico da saúde mental.

\section{Figura I - Filosofia habermasiana na saúde mental}

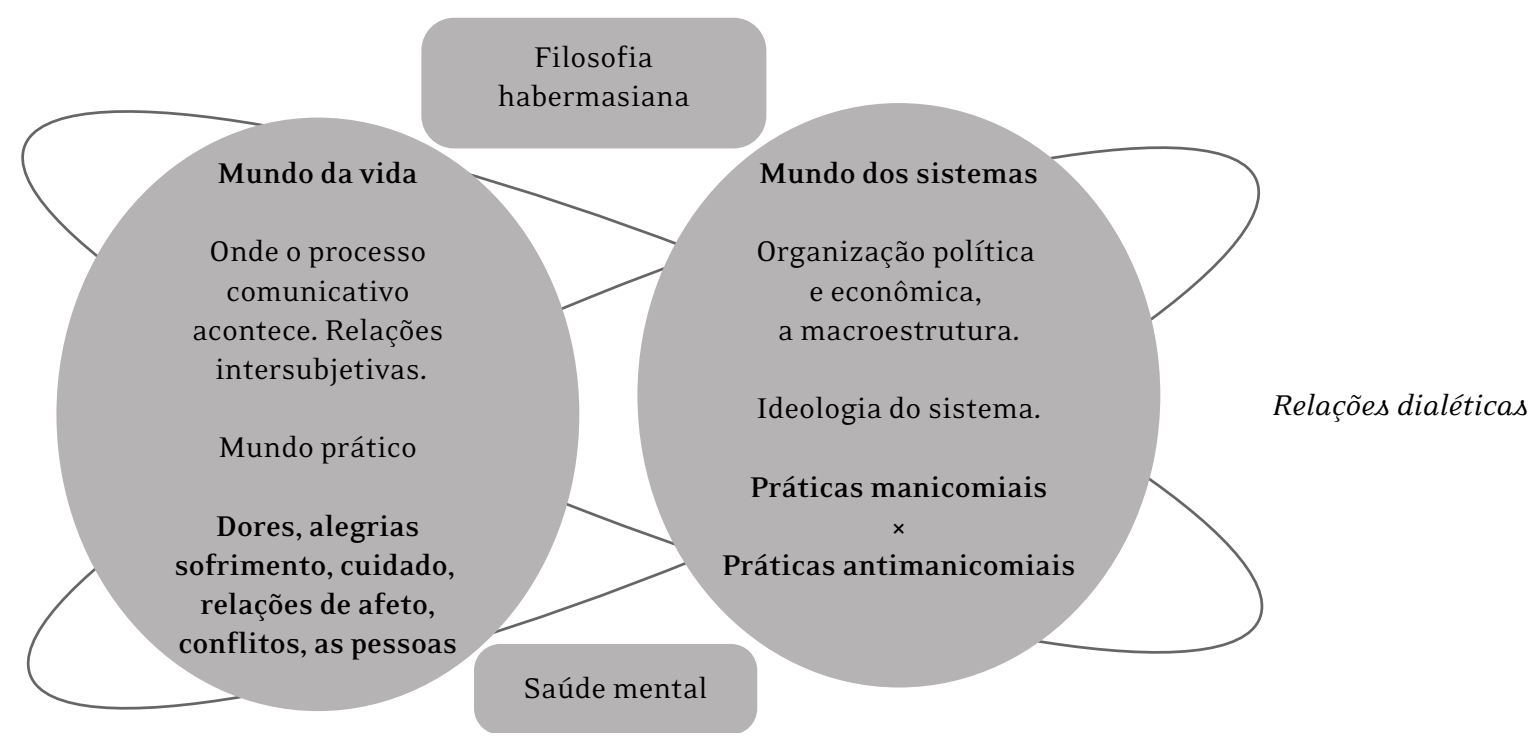

Fonte: adaptado de Fiedler (2006)

Nas práticas antimanicomiais existem serviços e profissionais que buscam efetivar os preceitos da Reforma Psiquiátrica e que fazem de seus microespaços territórios de luta a favor da Reforma, de modo a construir práticas em saúde mental que prezem pela liberdade e pelos vínculos familiares e comunitários. Já nas práticas manicomiais está a força ainda presente do manicômio, representada em ideias/posturas e valores nos processos de trabalho, na gestão dos serviços, na estrutura física, ou ainda nas relações de poder norteadas pelo modelo biomédico (que não é privilégio somente das/os médicas/os), manifestadas nas estratégias de atenção centradas no isolamento e na medicalização (Vasconcelos, 2007).

Nesse cenário, o agir comunicativo mostra grande potencial para transpor as tensões dialéticas entre esses mundos, materializadas em forças presentes no cotidiano e que estão em constante conflito. Acreditamos nos preceitos de que se os sujeitos tiverem possibilidade de analisar, 
discutir, problematizar o mundo da vida, poderão se "descolonizar" do sistema (Fiedler, 2006), pois, ao promover a integralidade no cuidado, fortalecemos os vínculos familiares e comunitários com vistas à autonomia dos sujeitos que experimentam o sofrimento psíquico, como expresso na Figura 2.

\section{Figura 2 - Práticas manicomiais e práticas antimanicomiais}

Práticas manicomiais

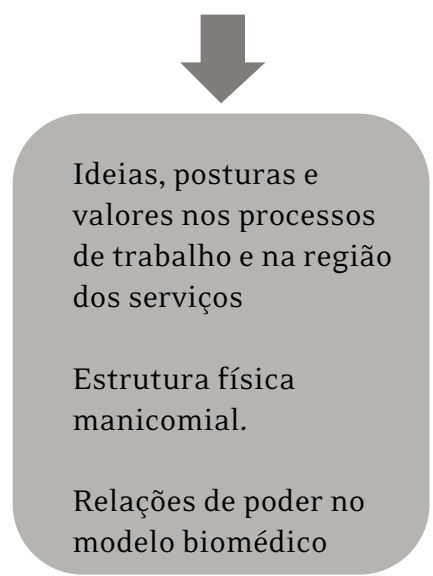

Práticas antimanicomiais

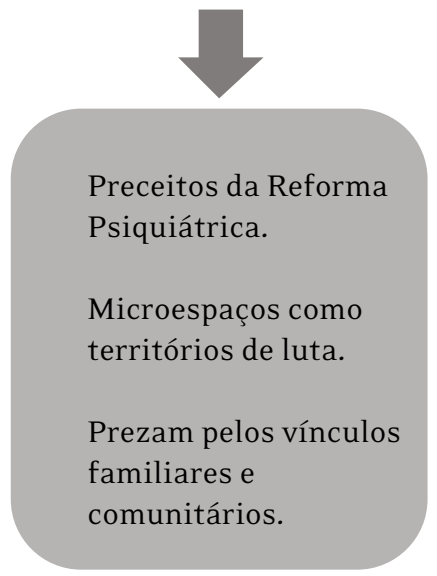

O conceito do mundo da vida apresentado por Habermas é vital para o exercício do agir comunicativo, pois só há diálogo onde há vida, desejo, movimento, e exista a ação linguística, sendo que nesta deve também estar contemplada as diversidades. As pessoas não oralizadas também expressam o potencial linguístico por meio de outras formas, como a língua de sinais, pela leitura labial, pelos movimentos corporais, por exemplo. Vale destacar que a razão comunicativa não é construída apenas na lógica racional, mas fundamentalmente na processualidade do diálogo. Requer envolvimento com uma ética preocupada com a solidariedade, que repudia o sofrimento e a opressão. Apresenta-se como um modelo político em que o discurso se manifesta na ação-reflexão-ação (Deslandes; Mitre, 2009).

A possibilidade do cuidado em liberdade passar pela construção do conhecimento sobre o "novo" é que, a partir de então, a filosofia, enquanto ciência, apresenta dois paradigmas para a construção do conhecimento: o paradigma da consciência e o paradigma da linguagem. Na filosofia da consciência, conhecer é uma relação entre a pessoa que conhece e o objeto a ser conhecido. Já na filosofia da linguagem, defendida por Habermas, existe uma relação entre a linguagem e o mundo (Habermas, 2002).

Dessa forma, é preciso produzir o entendimento sobre a Reforma Psiquiátrica com vistas a alcançar um consenso entre os sujeitos que dialogam e que desejam aprender sobre o cuidado em liberdade. Familiares e profissionais precisam estabelecer um espaço dialógico que gere um consenso, efetivando uma prática de cuidado transformadora da realidade posta para a realidade concebida/desejada do cuidado em saúde mental em liberdade, além do fortalecimento dos vínculos familiares e comunitários.

É preciso estabelecer um canal de troca de informações para alcançar o agir comunicativo.

Conceber o diálogo como intervenção profissional no campo da saúde mental é materializar uma prática profissional antimanicomial, o qual torna-se um modo de agir comunicativo, acionando as diferentes funções da comunicação (Habermas, 2002). Esse diálogo que comunica e potencializa as pessoas envolvidas no diálogo, expresso pela/o profissional assistente social com o familiar, tem como cenário de prática os Caps. 
Nesse contexto, concordamos com as ideias de Fiedler (2006), quando defende que há uma possibilidade de transformação social por meio da Teoria da Ação Comunicativa que Habermas formulou. Essa possibilidade de transformação faz uso do agir comunicativo como instrumento de trabalho e como possibilidade para a construção de valores humanos e para a transformação no modo de cuidar em saúde mental. Dessa forma, constrói-se uma possibilidade de efetivação dos preceitos do Movimento da Luta Antimanicomial, da Reforma Psiquiátrica e se fortalece a tríade familiar, usuárias/os e trabalhadoras/es.

A relação estabelecida entre uma/um usuária/o e/ ou familiar com uma/um profissional, por exemplo, apresenta capitais distintos de conhecimento, a partir de vivências e de técnicas. 0 objetivo não é o de construir uma concordância imediata nas opiniões, mas sim reconhecer as falas como importantes, oportunizando a discordância ou concordância pela utilização de argumentos válidos. Na diversidade de argumentos o encontro é fomentado, construindo mais legitimidade e riqueza para o entendimento por meio do respeito (Deslandes; Mitre, 2009).

Para esse consenso, faz-se necessário, conforme nos sugere Habermas (2002), compreender os aspectos culturais de cada família, que estão impregnados no mundo da vida das pessoas. Importante questionar: como, antes de existirem os serviços substitutivos como o Caps, além da alternativa do manicômio, as famílias exercitavam o cuidado com seus familiares em sofrimento, visto que anterior ao rompimento dos vínculos familiares por conta das internações psiquiátricas existiram também alegrias, conquistas positivas, que ficam soterradas pela dor, pela violência e pela opressão? Quando não há diálogo, não é possível reconstruir essas memórias, ou seja, estabelecemos apenas um receituário, uma fala prescritiva, determinando um "cumpra-se". Nesse monólogo, por inúmeras vezes, os familiares "descumprem" as “orientações”, não são "colaborativos". Mas será que realmente houve o entendimento ou sentido para as informações? Ocorreu sentido na "prescrição" para a/o ouvinte nesse processo?

A linguagem tem o potencial de aproximar ou afastar as pessoas, mesmo nos casos em que as falas são prescritivas, porém, deve haver compreensão, aproximação e vínculo para a construção do cuidado. Quando não se consegue atingir esse patamar, constroem-se rusgas, ranços e julgamentos de incapacidade para o cuidado em saúde mental, reforçando aqui a culpabilização das famílias.

O que se percebe é a necessidade do rompimento do modelo biomédico sobre os familiares, usuárias/ os, pois profissionais que acreditam possuir a fórmula perfeita para "ensinar" a cuidar esquecem-se de ouvir para também “aprender”, não favorecendo a prática da hermenêutica na comunicação, na construção de diálogos. Por vezes, profissionais imbuídos pelo poder biomédico desaprendem a ouvir, a aprender, a trocar, a experimentar, e junto com familiares e usuárias/os construir novas formas de cuidado, reiterando mais uma vez a culpabilização das famílias em detrimento da produção de novos modos de cuidar de usuárias/os e familiares.

\section{Agir educativo: intersecções possíveis com o agir comunicativo}

O educador e cientista social Paulo Freire expressa em suas obras a importância do diálogo como um dos processos que promovem liberdade, portanto, pauta seu agir educativo no diálogo, respeito e autonomia, demonstrando profundo vínculo com as contradições sociais ao problematizar situações de injustiça e despertar a consciência dos povos explorados na América Latina, África e Ásia por meio da educação. Nesse sentido, interage com o agir comunicativo de Jürgen Habermas, pois, mesmo com diferenças, os dois convergem no ideal de uma sociedade democrática, na qual possamos viver com dignidade e respeito (Pitano, 2017).

O pensamento de Paulo Freire transita por diversas áreas do conhecimento, por exemplo, as ciências sociais, humanas e da saúde, devido a seu potencial transversalizante (Sevalho, 2017). Especialmente na saúde mental, ele é reconhecido devido ao seu caráter dialógico, dialético e relacional, por defender o direito das minorias, dos excluídos, e seus construtos se articulam ao desejo de que a clínica antimanicomial se faça na pluralidade, na horizontalidade, e promova movimentos relacionais fomentando a interdisciplinaridade e integralidade da atenção em saúde. 
Para Freire (2013), citando Eduardo Nicol, aponta quatro relações constitutivas do conhecimento: a gnosiológica, a lógica, a histórica e a dialógica, pois defende que "todo ato de pensar exige um sujeito que pensa, um objeto pensado, que mediatiza o primeiro sujeito do segundo, e a comunicação entre ambos, que se dá através de signos linguísticos" (Freire, 2013, p. 66). Nessa discussão, concebemos que os sujeitos pensantes são as/os familiares, as/os usuárias/ os e as/os assistentes sociais. 0 objeto pensado é a interação entre educação, comunicação e cuidado a fim de dirimir o sofrimento da/o usuária/o. Desse modo, para o processo de construção do conhecimento sobre as novas formas de cuidar em saúde mental junto de familiares, a partir das relações dialógicas, existem dois caminhos, expressos na Figura 3.

Figura 3 - Processo de construção de conhecimento a partir das relações dialógicas estabelecidas entre usuárioassistente social-família

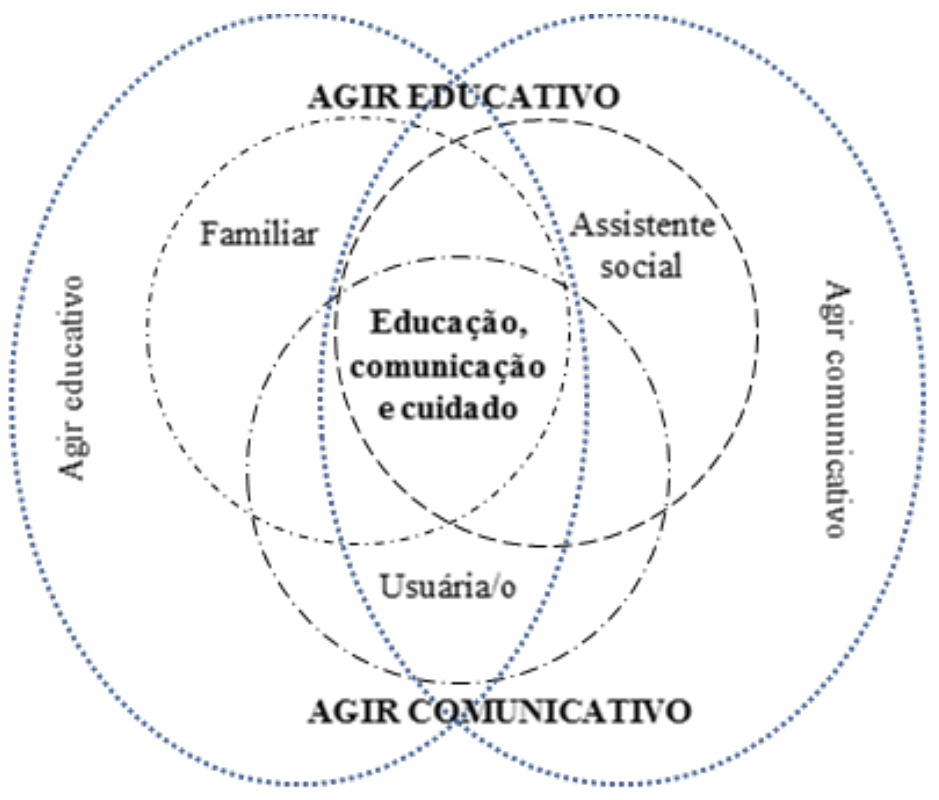

No foco deste texto, podemos pensar que quando $\mathrm{a} / \mathrm{o}$ assistente social (primeiro sujeito) utiliza seu arcabouço teórico-metodológico, este deve ser estruturado na lógica antimanicomial diante do sofrimento expresso pela/o usuária/o, de modo a ressignificar a inter-relação entre educação, comunicação e cuidado (objeto pensado), e então a/o familiar (segundo sujeito) poderá intervir na relação com as/os usuárias/os, construindo novos conhecimentos para o cuidado, tanto para familiares, quanto para assistentes sociais. Ou quando a/o familiar (primeiro sujeito) utiliza também seu arcabouço de experiência de vida diante do sofrimento da/o usuária/o (objeto pensado), colabora para que as/os assistentes sociais (segundo sujeito) possam, por meio da mediatização das relações, ampliar seu arcabouço teórico-metodológico para novas abordagens enquanto profissionais da saúde.

Há pessoas que acreditam que não podem pensar sozinhas, não sem a co-participação de outras pessoas. Assim, existe um "pensamos" em detrimento de um "penso", sendo que ele é do coletivo para o individual. Essa co-participação é materializada no ato da comunicação e, nesse contexto, o objeto a ser pensado torna-se um mediatizador da comunicação, e na ausência dessa relação não existe comunicação, mas sim o fortalecimento da identidade de paciente para os comunicados emitidos (Freire, 2013).

É importante destacar que o diálogo é descaracterizado de sua função quando existe a passividade das pessoas, tendo aí a máxima da verborragia, e não a relação dialógica que Freire 
(2015) propõe. O que por vezes se observa na prática das/os assistentes sociais é a absorção do modelo biomédico, ao ponto de "prescrever" encaminhamentos e orientações, ou no outro extremo, de desconsiderar a subjetividade e as intersubjetividades propostas no acompanhamento socioassistencial. Podemos dizer que pouco se acompanha socioassistencialmente as pessoas, na lógica de articular possibilidade para transpor as vulnerabilidades geracionais que se manifestam no cotidiano das famílias, identificando-se intervenções em que se almejam resultados e se segue para a próxima situação, fragmentando o cuidado e reforçando ainda hoje as "situações problema".

A escuta é parte fundamental das relações dialógicas, tendo em vista que não é falando aos outros, prescritivamente, que oportunizaremos a escuta; exercitar a escuta é, sim, o momento em que mais se aprende a falar com as pessoas. A escuta tolerante e crítica é falar com as pessoas, mesmo quando, porventura, precisa-se falar para as pessoas (Freire, 2011).

Como mencionado anteriormente, a escuta é parte integrante e fundamental da perspectiva antimanicomial, sendo fundamento básico para o agir educativo mediatizado pelo diálogo que, segundo Freire (2011, 2013, 2015), se aproxima do pensamento antimanicomial, quando o autor propõe que o diálogo requer a horizontalidade das relações interpessoais. A horizontalidade requer respeito às diferenças, autonomia e aprendizado mútuo. Dessa forma, o agir educativo, a partir das relações dialógicas, promove um espaço acolhedor e promotor de saúde mental, especialmente pelo fortalecimento dos vínculos familiares e comunitários.

A construção dos sujeitos ocorre na palavra, na ação-reflexão, e a palavra nunca pode ser dita num ato de prescrição, sendo ela um direito de todas e todos. Portanto, o diálogo é muito mais do que o encontro entre as pessoas, tornando-se um caminho pelo qual as pessoas ganham significados enquanto pessoas (Freire, 2015).

Esse processo de aprendizagem proposto a partir do agir educativo está alicerçado na educação popular em saúde, a qual prevê que, independentemente do nível de escolaridade, os papéis ocupados por educadoras/es e educandas/ os seja fluído, ou seja, nada sólido e estático; logo, que o aprendizado seja uma via de duas mãos, em que possamos construir a “"outredade' do 'não eu', ou do tu, que faça assumir a radicalidade de meu eu" (Freire, 2011, p. 41). Nessa lógica, eu aprendo com você, você aprende comigo, e nós em comunhão podemos ensinar novos pares, para que a transformação aconteça e permaneça.

A educação diz respeito à formação e à expansão da democracia e da cidadania, segundo Freire e Habermas, que estão preocupados em entender os elementos subjetivos e comunicacionais das relações interpessoais, bem como as possibilidades de suas transformações (Pitano, 2017). Dessa forma, ambos oferecem subsídio para compreendermos a relação dialógica que se estabelece, ou não, entre assistentes sociais e familiares nos Caps.

Que desse cenário germine as ideias da Reforma Psiquiátrica, com potencial de fortalecer a autonomia das famílias para o cuidado em saúde mental nos serviços substitutivos, a fim de que nessa relação seja possível despertar a consciência, para que novos pares ampliem a compreensão de que a liberdade, o cuidado e a autonomia podem curar as feridas produzidas por séculos de violência e exclusão da lógica manicomial.

\section{Agir educativo-comunicativo em saúde mental: possibilidade de efetivar ações considerando a integralidade da atenção}

Com a pretensão de colocar em diálogo o "agir comunicativo" e o "agir educativo", acreditamos que esses dois modos de agir, em sinergia, podem potencializar o cuidado em saúde mental em liberdade, com base comunitária.

Para Habermas (2002), as funções da linguagem demonstram o potencial em oportunizar a validade do tema discutido e expressam o processo de interlocução entre as funções a todo tempo. Validade diferencia-se aqui de verdade, pois o autor apresenta o conceito de validade como resultado daquilo que é consenso entre duas/dois interlocutoras/es. Assim, quais as "validades" que temos nos diálogos sobre os cuidados em saúde 
mental? Quais as verdades que se apontam como indicadores do que é cuidar em saúde mental sob a óptica antimanicomial, ou ainda é reforçada a prática manicomial em serviços substitutivos?

Pensando as três funções da linguagem apresentadas por Habermas (2002) - representativa, interativa e expressiva -, podemos apontar que a função representativa da linguagem está caracterizada na concepção de Reforma Psiquiátrica que as/os assistentes sociais expressam, enquanto a função interativa está materializada na relação entre as/os assistentes sociais e familiares e/ou usuárias/os, na relação entre as pessoas. Por fim, a função expressiva caracteriza-se como a concepção que as/os assistentes sociais possuem sobre o processo de trabalho no Caps. Essas três funções da linguagem são construídas na perspectiva de efetivar o agir educativo-comunicativo na relação das/os assistentes sociais com o/a familiar no Caps. A Figura 4 expressa uma representação dessa compreensão

\section{Figura 4 - Agir educativo-comunicativo e a linguagem representativa, interativa e expressiva da/o assistente social junto de familiares de usuárias/os dos Caps}

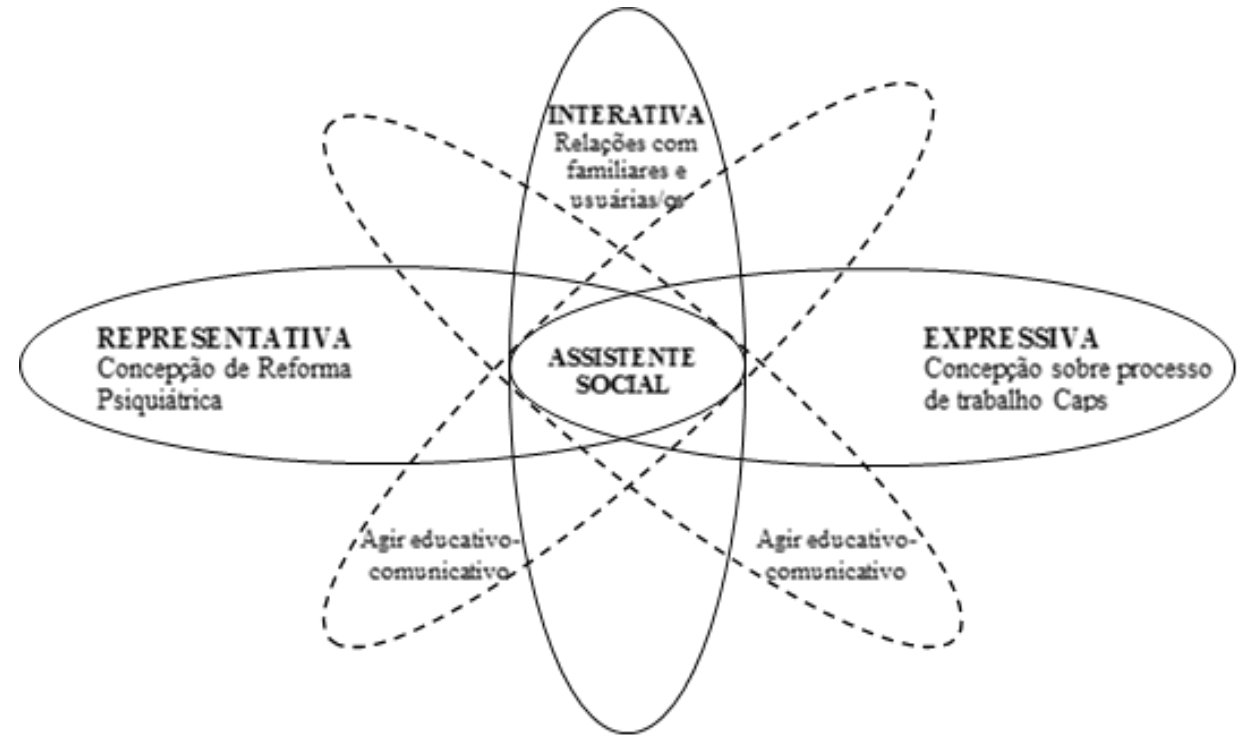

Ao estabelecer a relação entre o pensamento de Habermas e de Freire, emergem categorias fundamentais para a construção do agir educativocomunicativo no processo de trabalho das/os assistentes sociais junto com as famílias de usuárias/os de Caps, tais como: a escuta, o diálogo, a linguagem, a cultura, a horizontalidade e a educação. Essas categorias estão inter-relacionadas para a construção de um agir educativo-comunicativo que visa a produção do cuidado. Nesse sentido, o agir educativo-comunicativo caracteriza-se como uma ação norteadora para a produção de cuidado em saúde mental, sobretudo para o fortalecimento dos vínculos familiares e comunitários que o cuidado em liberdade oportuniza.
Na conjuntura política atual, na qual experimentamos o desmonte de importantes políticas públicas, entre elas as de saúde mental, além do avanço do campo político de extrema direita, experimentamos a redução dos direitos sociais e uma hiperindividualização que, por vezes, promove a cultura do ódio e do medo, construindo relações sociais fragilizadas. Ouvir as pessoas tem sido cada vez mais difícil.

Existe a verborragia de verdades absolutas, em que impera o desejo de surdez - a crescente do fascismo (Tiburi, 2016); contrapondo-se à concepção que emerge do fascismo, a escuta é condição sine qua non para a prática educativa. Quem aprende a escutar dificilmente falará impositivamente; mesmo nas discordâncias e 
contra-argumentações, falará com as pessoas, como aquelas que escutam a sua fala crítica, e não somente como objetos de seu discurso (Freire, 2011).

Considerar que quem escuta aprende e quem fala comunica algo é a condição para não considerar as/ os "ouvintes" como objeto, e sim como uma pessoa que busca comunicar algo e, para tanto, utiliza todos os seus recursos disponíveis: a fala, o corpo, ou seja, as mais diferentes linguagens. A escuta favorece a construção do diálogo, rompendo com os discursos prescritivos, em que a/o assistente social pode desenvolver com os familiares de usuárias/os de Caps uma escuta acolhedora, política, comprometida com o desejo de ir além do que está sendo dito.

Colocar o diálogo como forma de ação pode ser transformador nas relações que estão estabelecidas, ao considerarmos a interação que o diálogo oportuniza - a transformação é para quem escuta e para quem fala. Toda relação é constituída por sujeitos que constroem suas experiências por meio do diálogo, a partir do qual o exercício do consenso fortalece os vínculos entre profissionais e familiares, oportuniza a produção do cuidado e, como fruto dessa relação dialógica, busca construir o cuidado em saúde mental que consideramos produto final do agir educativo-comunicativo aqui proposto.

Assim como a escuta e o diálogo, a linguagem nesse contexto também é primordial, visto que as palavras carregam pesos diferenciados, e a intenção é sempre a de aproximar ideias e palavras e problematizar as diferenças de significados, valorizando a riqueza de sentidos e, especialmente, abrindo espaço para a práxis crítico-reflexiva (Freire, 2013).

Outra categoria importante para o agir educativo-comunicativo é a cultura, que influencia diretamente cada grupo familiar, que por sua vez apresenta um modo de viver particular: uma religião, uma biografia, um espaço geográfico, uma linguagem, entre outros fatores que constroem sua cultura. $\mathrm{O}$ universo a partir do qual Paulo Freire analisa a educação é a cultura, enfatizando um vínculo culturaconscientização-liberdade (Freire, 2014).

Compreendendo que o processo de aprendizagem é um processo de mão dupla, todas as pessoas aprendem a cuidar das pessoas que sofrem, assim como as pessoas que sofrem, compartilhando as suas experiências, oportunizam o conhecimento sobre a vida e suas experiências. Faz-se necessário que os profissionais, em especial as/os assistentes sociais, utilizem o agir educativo-comunicativo buscando não anular a cultura de cada grupo familiar, mas sim acionar essa cultura a favor do cuidado em liberdade.

Não é salutar manter práticas profissionais que reduzem as pessoas a objetos, que resumem o seu sofrimento à sua doença, porém, observa-se práticas organizadas com base em necessidades das/os profissionais para os seus procedimentos, privilegiando as técnicas em vez dos sucessos terapêuticos concretos na vida das pessoas, processos que vem de encontro à lógica da integralidade da atenção em saúde (Mattos, 2009).

As famílias das/os usuárias/os de Caps cuidam das pessoas que sofrem por uma vida inteira, tendo o agir educativo-comunicativo como objetivo potencializados desse cuidado. A transposição dos sofrimentos das/os usuárias/os dos Caps, em parceria com familiares, torna-se possível por meio do empoderamento e da educação para o cuidado.

No campo da saúde mental, o conceito de empoderamento é uma perspectiva de fortalecimento do poder, de participação e de organização, colocando a/o usuária/o e a/o familiar como protagonistas. Também pode ser considerado como uma oportunidade de defesa de direitos, de mudança de uma cultura referente a saúde mental ainda presente em nossa sociedade (Vasconcelos, 2007).

Para além dos encaminhamentos, articulações de rede e mecanismos burocráticos que fazem parte do processo de trabalho das/os assistentes sociais, com o agir educativo-comunicativo propomos romper com a lógica mercantilista de saúde, focada somente na doença e privilegiando protocolos e o modelo biomédico. O cuidado em saúde mental, a partir da Reforma Psiquiátrica e enquanto campo de atuação, requer intervenções mais humanas, focalizadas nas relações entre as pessoas. Cada pessoa carrega em si sua história e sua cultura, contexto intenso que precisa ser considerado. "A atenção psicossocial propõe uma ampliação e uma alteração na forma de entender o problema, atribuindo importância ao sujeito como protagonista do tratamento, além de proporcionar dispositivos de reinserção social” (Bermudez; Siqueira-Batista, 2017, p. 912). 
A educação enquanto uma categoria do agir educativo-comunicativo prioriza a construção de uma relação histórica entre a desumanização e humanização das pessoas, não resultando de uma "ordem" injusta que gera a violência dos opressores contra as/os oprimidas/os (Freire, 2015). Essa relação entre oprimida/o e opressor/a no campo da saúde mental é caracterizada pela relação de poder expressa por profissionais com usuárias/os e familiares, profissionais que desenvolvem seu trabalho na contramão do agir educativo-comunicativo, podendo também ser expressado na relação de poder e submissão entre as profissões das equipes multiprofissionais (Basaglia, 2009), resquícios ainda do modelo manicomial e do poder biomédico.

É preciso que as intervenções profissionais tenham como objetivo ampliar os limites do andar da vida das pessoas, sendo esse cenário de fundamental importância, porque compreende o sofrimento no contexto em que ele se manifesta. É preciso a construção de um cuidado que esteja preocupado em descolonizar, reduzir as tutelas, abandonar a vigia e o controle, oportunizando a emancipação e autonomia das pessoas em sofrimento (Mattos, 2009).

A educação no agir educativo-comunicativo tem o potencial de promover a autonomia das famílias para o exercício do cuidado em saúde mental, além de fomentar nas/nos assistentes sociais a diversidade de aprendizados sobre o cuidado, considerando os aspectos da cultura que ensinam um modo de cuidar em diferentes cenários da atenção à saúde. Nesse processo é possível o exercício da relação entre cuidado e educação: cuidamos educando e educamos cuidando (Ferraz et al., 2005), pois precisamos lembrar que o cuidado está vinculado a existência humana, desde o nascimento até a morte, e está presente no sentido da vida. Se não estiver assim concebido pelas pessoas, acabará por prejudicar a si mesmo e todas/os à sua volta (Boff, 2014).

Logo, além das categorias que emergem da relação entre Habermas e Freire, é possível acrescentar o cuidado enquanto categoria também fundamental para o agir educativo-comunicativo. O cuidado, na saúde mental, pode ainda ser concebido como integrativo, em que as ações realizadas oportunizem "perceber/percebendose, ouvir/perscrutando e tocar/sentindo o outro em seu contexto e nas dimensões de seu espaço" (Ferraz et al., 2005, p. 608).

O cuidado promovido pelo agir educativocomunicativo também está inserido na esfera dos direitos, caracterizando-se como uma relação política que exige horizontalidade além de dialogicidade (Freire, 2015). A relação do aprender a cuidar é uma relação horizontal, de troca, de crescimento mútuo, entre profissionais, familiares, usuárias e usuários, com o objetivo comum de cuidar em liberdade e diminuir os sofrimentos, pois, numa relação, ambos os lados sofrem.

Nessa relação, mais do que agregar o cuidado ao trabalho profissional, trata-se de valorizar o modo de cuidar exercido pelas famílias, compreendendo o "ensinar" como o movimento de que quem ensina aprende ao ensinar, e quem aprende ensina ao aprender. Assim, não se reproduzem as relações hierarquizadas daquele que aprende e aquele que ensina, tal como na educação bancária (Freire, 2011). Ensinar e aprender a cuidar poderá ser o caminho para o fortalecimento dos vínculos comunitários e familiares, além de fomentar a Reforma Psiquiátrica como um modelo de cuidado em liberdade efetivo.

O cuidado, quando se manifesta a partir de uma construção crítica, política e na lógica da integralidade, oportuniza a ressignificação dos sujeitos numa relação democrática e cidadã entre profissional e usuária/o e/ou familiar. Não reforça uma ilusão da mediocridade do individualismo, mas constrói um processo que fortalece a ética e a mudança e valoriza as expressões dos sujeitos em relação à garantia de seus direitos (Faleiros, 2013).

Duas correntes expressam a ruptura com o assistencialismo vinculado ao cuidado: o movimento feminista e o movimento dos direitos humanos, ambos depositando a crença de que cuidado está articulado intrinsecamente às necessidades humanas, destacando a historicidade desse processo. 0 cuidado como um valor político, e não moral, passa pela perspectiva da discussão de gênero e pela discussão dos direitos humanos. Cuidar e ser cuidado faz parte da condição humana, e enquanto direito garante a sobrevivência de cada pessoa (Faleiros, 2013).

A palavra "cuidado" é pouco apresentada nas produções científicas do serviço social (Faleiros, 
2013), porque compreendemos que as questões subjetivas, por vezes, não se apresentam como foco principal de intervenção da/o assistente social, mas compreende-se que o cuidado é um direito e, como tal, poderá ser a porta de entrada para novos diálogos com as famílias, novas formas de fortalecimento da Reforma Psiquiátrica, com o cuidado materializado em um Estado de direito e vinculado à autonomia, à possibilidade de rever discriminações e fomentar o desenvolvimento da autoestima. Esse movimento está fundado na perspectiva humanizadora da Política Nacional de Assistência Social (Faleiros, 2013).

Nessa lógica, o cuidado em saúde mental requer abordagens que se coloquem a favor da vida, da liberdade, da valorização das diversidades, da dignidade, da bioética e do respeito, ou seja, dos direitos humanos. Há que se estabelecer relações vivas, que promovam afetos entre familiares e profissionais, que produzam saúde e que não cultivem a doença, a dor e o sofrimento. Cuidar é também uma atitude, extrapola o ato em si do cuidado, "representa uma atitude de ocupação, preocupação, de responsabilização e de envolvimento afetivo com o outro" (Boff, 2014, p. 33).

Não apostar no potencial das famílias para o cuidado em saúde mental é subsidiar uma condição de subserviência, é colaborar para a manutenção do modelo manicomial, em que nutrir a miséria, é conservar o status quo de poder pré-estabelecido, em que existe alguém que conscientemente colabora para a manutenção das subalternidades entre as pessoas, assim, não haverá rompimento do ciclo de dependência das famílias que a institucionalização da loucura construiu há séculos no imaginário social.

Dessa forma, observar a relação entre as categorias apresentadas por Habermas e Freire no cotidiano de atuação profissional com familiares inseridos nos Caps pode ser uma estratégia com potencialidade para consolidar a participação ativa das famílias no cuidado em saúde mental, que por séculos foram apartadas desse processo.

\section{Considerações finais}

A partir da perspectiva do agir educativocomunicativo, o diálogo e a escuta apresentam-se como estratégias políticas, terapêuticas, antimanicomiais e de resistência importantes para o cuidado em saúde mental. Além disso, a cultura tem papel fundamental para manifestar um modo de estar no mundo, um modo que indica vulnerabilidades e potencialidades para o empoderamento e o exercício de cuidar em saúde mental.

Enquanto instrumentalidade da dimensão técnicooperativa de assistentes sociais, o agir educativocomunicativo nos convida a estabelecer relações mais horizontais entre familiares e assistentes sociais, para que o cuidado em saúde mental em liberdade e na perspectiva comunitária possa ser concretizado.

Romper com o poder biomédico, com a lógica prescritiva que impera na postura de grande parte dos profissionais da saúde é urgente, pois faz-se necessário uma intervenção potente de educação permanente em saúde com as/os assistentes sociais, no sentido de ampliar a perspectiva histórica sobre a Reforma Psiquiátrica. Além disso, é importante fomentar um conceito de educação nas relações humanas que seja emancipadora e, por conseguinte, antimanicomial. Dessa forma, há possibilidade de oportunizar a hipervalorização da dimensão éticopolítica do serviço social, a partir da compreensão do cuidado enquanto direito e da defesa incondicional dos direitos humanos em saúde mental. Como expresso neste ensaio, as dimensões do serviço social são interatuantes, logo, a dimensão ético-política influenciará diretamente a dimensão técnico-operativa, construindo uma instrumentalidade interventiva baseada na dialogicidade, na horizontalidade e na valorização das culturas.

$\mathrm{O}$ agir educativo-comunicativo coloca-se como a possibilidade de transformar o modo de cuidar em saúde mental, em que a mediação oportunizará a construção de novos conhecimentos e, por consequência, novos modos de cuidar em liberdade com base comunitária em serviços substitutivos, como o Caps. Sendo assim, a integralidade se fará presente, promovendo saúde mental. Portanto, pensar o agir educativo-comunicativo na relação entre assistentes sociais e familiares de usuárias/os de Caps é materializar a possibilidade de fortalecer os vínculos comunitários e familiares, além de fomentar os preceitos da Reforma Psiquiátrica e da Luta Antimanicomial no cuidado em saúde mental. 


\section{Referências}

BASAGLIA, F. A instituição negada. 3. ed. Rio de Janeiro: Graal, 2009.

BERMUDEZ, K. M.; SIQUEIRA-BATISTA, R. “Um monte de buracos amarrados com barbantes": o conceito de rede para os profissionais da saúde mental. Saúde e Sociedade, São Paulo, v. 26, n. 4, p. 904919, 2017. Disponível em: <http://bit. ly/3oCeytX>. Acesso em: 27 ago. 2019.

BOFF, L. Saber cuidar: ética do humano: compaixão pela terra. 20. ed. Petrópolis: Vozes, 2014.

CESTARI, M. E. Agir comunicativo, educação e conhecimento: uma aproximação ao pensamento de Habermas. Revista Brasileira de Enfermagem, Brasília, DF, v. 55, n. 4, p. 430433, 2002.

Disponível em: <http://bit.ly/2HtQVfD>. Acesso em: 23 set. 2017.

DESLANDES, S. F.; MITRE, R. M. A. Processo comunicativo e humanização em saúde. Interface: Comunicação, Saúde, Educação, Botucatu, v. 13, p. 641649, 2009. Suplemento 1. Disponível em: <http://bit.ly/2HvsGNQ>. Acesso em: 23 set. 2017.

FALEIROS, V. P. Desafios de cuidar em serviço social: uma perspectiva crítica. Katálysis, Florianópolis, v. 16, p. 8391, 2013. Número especial. Disponível em: <http://bit.ly/3267tBX>. Acesso em: 23 set. 2017.

FERRAZ, F. et al. Cuidar-educando em enfermagem: passaporte para o aprender/ educar/cuidar em saúde. Revista Brasileira de Enfermagem, Brasília, DF, v. 58, n. 5, p. 6o7610, 2005. Disponível em: <http://bit.ly/2NBxqFQ>. Acesso em: 23 set. 2017.

FIEDLER, R. C. P. A teoria da ação comunicativa de Habermas e uma nova proposta de desenvolvimento e emancipação do humano. Revista Educação, Guarulhos, v. 1, n. 1, p. 9310o, 2006. Disponível em: <http://bit.ly/2MEuPen>. Acesso em: 23 set. 2017.

FREIRE, P. Pedagogia da autonomia: saberes necessários à prática educativa. 43. ed. São Paulo: Paz e Terra, 2011.

FREIRE, P. Extensão ou comunicação? 18. ed. Rio de Janeiro: Paz e Terra, 2013.
FREIRE, P. Ação cultural para a liberdade e outros escritos. Rio de Janeiro: Paz e Terra, 2014.

FREIRE, P. Pedagogia do oprimido. 59. ed. Rio de Janeiro: Paz e Terra, 2015.

GUERRA, Y.; BACKX, S.; SANTOS, C. M. A

dimensão técnico-operativa no serviço social: desafios contemporâneos. São Paulo: Cortez, 2017.

HABERMAS, J. Pensamento pós-metafísico. 5. ed. Rio de Janeiro: Tempo Brasileiro, 2002.

LIMA, C. Á. O Centro de Atenção Psicossocial (Caps) e a reinvenção do lugar de cuidado em saúde mental: contribuições e perspectivas para o serviço social. 2015. Dissertação (Mestrado em Serviço Social) - Pontifícia Universidade Católica, São Paulo, 2015. Disponível em: <http://bit. ly/32cV2Vj>. Acesso em: 29 set. 2018.

MATTOS, R. A. Princípios do Sistema Único de Saúde (SUS) e a humanização das práticas de saúde. Interface: Comunicação, Saúde, Educação, Botucatu, v. 13, p. 771780, 2009. Suplemento 1. Disponível em: <http://bit.ly/2Zn2TTa>. Acesso em: 23 fev. 2019.

PIMENTA, E. S.; ROMAGNOLI, R. C. A relação com as famílias no tratamento dos portadores de transtorno mental realizado no Centro de Atenção Psicossocial. Pesquisas e Práticas Psicossociais, São João Del Rey, v. 3, n. 1, p. 7584, 2008.

Disponível em: <http://bit.ly/2PgOgjV >. Acesso em: 23 set. 2017.

PITANO, S. C. Problematizando referências para a educação popular: Paulo Freire e Jürgen Habermas. Revista Sul-Americana de Filosofia e Educação, Brasília, DF, n. 28, p. 104119, 2017. Disponível em: <http://bit.ly/2Zt65aU>. Acesso em: 23 fev. 2019.

ROSA, N. C. Freire e Habermas: contribuições à reflexão da práxis educativa na contemporaneidade. In: SEMINÁRIO

NACIONAL DIÁLOGOS COM PAULO FREIRE: CONTRIBUIÇÕES À PRÁXIS EDUCATIVA NA CONTEMPORANEIDADE, 9., 2015, Igrejinha. Anais... Taquara: Faculdades Integradas de Taquara, 2015. p. 18. Disponível em: <http://bit. ly/2KWHxmE>. Acesso em: 18 jun. 2017. 
SANTOS, Q. G. et al. Os serviços de saúde mental na reforma psiquiátrica brasileira sob a ótica familiar: uma revisão integrativa. Revista de Pesquisa Cuidado é Fundamental, Rio de Janeiro, v. 8, n. 1, p. 3740-3757, 2016. Disponível em: <http://bit.ly/33VU7Km>. Acesso em: 23 set. 2017.

SEVALHO, G. O conceito de vulnerabilidade e a educação em saúde fundamentada em Paulo Freire. Interface: Comunicação, Saúde, Educação, Botucatu, v. 22, n. 64, p. 177188, 2017. Disponível em: <http://bit.ly/2HvwRcu>.

Acesso em: 23 fev. 2019.

TIBURI, M. Como conversar com um fascista. 8. ed. Rio de Janeiro: Record, 2016.
TUON, R. E. A. C. A inserção e atuação do assistente social nos Centros de Atenção Psicossocial para Álcool e Drogas - Capsad. 2011. Dissertação (Mestrado em Serviço Social) - Pontifícia Universidade Católica, São Paulo, 2011. Disponível em: <http://bit.ly/2HrsjUy>. Acesso em: 23 set. 2017.

VASCONCELOS, E. M. Dispositivos associativos de luta e empoderamento de usuários, familiares e trabalhadores em saúde mental no Brasil.

Vivência: Revista de Antropologia, Lagoa Nova, v. 1, n. 32, p. 173206, 2007.

VASCONCELOS, E. M. Reforma psiquiátrica, tempos sombrios e resistência: diálogos com o marxismo e o serviço social. Campinas: Papel Social, 2016.

\section{Contribuição dos autores}

Cardozo foi a pesquisadora principal do estudo que originou este artigo, sob orientação de Ferraz, com quem também planejou e executou a pesquisa.

Silvio Yasui: participou na orientação, leitura e revisão da confecção do manuscrito. Jacks Soratto: participou na leitura e revisão da confecção do manuscrito.

Diego Floriano: participou na leitura e revisão da confecção do manuscrito.

Recebido: 09/05/2019

Reapresentado: 30/06/2019

Aprovado: 09/07/2019 